\title{
Further Exploration of Terrestrial Vegetation Response(s) to ENSO Variability Using a Mechanistic Vegetation Simulation Model
}

\author{
M. Manobavan ${ }^{1 *}$ and N. S. Lucas ${ }^{2}$ \\ ${ }^{1}$ Centre for Earth and Environmental Science Research, Kingston University, Penrhyn Road, \\ Kingston upon Thames, Surrey, KT1 2EE, UK \\ ${ }^{2}$ University of Wales, Swansea, Singleton Park, Swansea, Wales, SA3 3DQ, UK
}

\begin{abstract}
The need for analysis of terrestrial vegetation interactions and interannual climate variability such as the ENSO is paramount as terrestrial vegetation is an important boundary condition for the climate system, and is the primary interactive surface for the atmosphere. Contemporary investigations have been focusing on non-synergistic investigations to approach this within the Earth System bar a few. A complete understanding of these interconnective processes within the Earth System is impossible without the synergistic approach involving the incorporation of remotely sensed data. This paper follows on the research of Manobavan et al. (2003), who using a synergistic approach showed/hypothesised that terrestrial South American vegetation may have become resilient to interannual climatic perturbations by the El Niño Southern Oscillation (ENSO). This paper further explores this possibility via simulations performed using the Hybrid Version 4.1, which was conditioned to incorporate ENSO related climatic variability. The results of this simulation modelling exercise support this hypothesis and show that the interannual perturbations such as the ENSO enhance the homeostatic property of the system rather than hinder it within its geophysiological limits. Moreover, this paper combines modelling and geophysiology thus attempting to provide a 'holistic' mechanistic explanation to the speculated behaviour of the terrestrial vegetation under perturbation by the ENSO.
\end{abstract}

Keywords: Geophysiological limits, interannual climatic variability, synergistic approach, vegetation simulation modelling

\section{Introduction}

Anthropogenic forcing of the Earth’s climate system through the release of greenhouse gases such as carbon dioxide $\left(\mathrm{CO}_{2}\right)$ into the atmosphere has resulted in the need for understanding the likely impacts of any future climate changes on the Earth System (Claussen et al., 2001; IPCC, 2001). The land surface is an important boundary condition for the climate system, and vegetation the primary terrestrial interactive surface for the atmosphere (Friend and White, 2000). Therefore the need for analysis of land surface-vegetation interactions and climate is paramount. Of particular concern in this regard is the shift of the El Niño Southern Oscillation (ENSO), which is the largest known interannual climatic variability mechanism at global scales (Dawson and O'Hare, 2000), to frequent warm (El Niño) episodes. This shift is attributed to enhanced global warming (IPCC, 2001) and is expected to influence terrestrial processes on a wider scale (Knorr, 2000).

Previous modelling studies have reported a reduction in terrestrial photosynthetic biomass corresponding to El Niño events (e.g. Cox et al., 2000; Knorr, 2000; Ni, et al., 2000). A 'notable feature' of these investigations is the lack of integration of real-world data for the terrestrial systems. As Plummer

* Corresponding author: b4v4n@yahoo.co.uk
(2000) observes, any understanding of terrestrial ecosystem processes is limited without use of remotely sensed data. However, remote sensing studies in the past have tended to focus on the derivation of biophysical parameters in terrestrial ecosystems (e.g. Hansen and Schjoerring, 2003; Boyd and Duane, 2001) or in investigating the relationship between climatic patterns and remotely sensed terrestrial vegetation data (e.g. Wellens, 1997; Li and Kafatos, 2000), often without reference to terrestrial ecological processes. Similarly, ecological process studies in Earth System Science have generally been undertaken without reference to remote sensing (e.g. Woodward et al., 1995; Haxeltine and Prentice, 1996; Xiao et al., 1998; Potter and Klooster, 1999; Peng, 2000). It is emphasised that an approach that involves the synergistic application of these two disciplines is necessary to enable a better understanding of the Earth System (Plummer, 2000). Moreover, as Lovelock (1995) emphasizes, the most appropriate way forward towards developing a much more comprehensive understanding of the Earth System is through 'geophysiology', which is looking at the interconnected processes within the Earth System from a physiological perspective.

A recent example of an attempt towards a synergistic approach to understand terrestrial vegetation responses to inter-annual climatic forcing, is the study by Manobavan et al. (2003) which was based on time-series modelling of National Oceanographic and Atmospheric Administration (NOAA) 
Advanced Very High Resolution Radiometer (AVHRR) Normalized Difference Vegetation Index (NDVI) data for terrestrial South America. They established that the South American vegetation could have become resilient to ENSO perturbations over time. The findings of Manobavan et al. (2003) are supported by Arora (2003). However, the investigation of Manobavan et al. (2003) does not explain the how the resilience could have arisen in terms of vegetation dynamics from a mechanistic-geophysiological perspective.

In that respect, this paper builds on the work of Manobavan et al. (2003) and attempts to explore the possibilities of increased resilience in the terrestrial South American vegetation by coupling ENSO related climatic variability to a simulation model (Hybrid Version 4.1). The Hybrid Version 4.1 (Friend and White, 2000), is a mechanistic vegetation simulation model capable of simulating the transient nature of climate and ecosystem interaction as opposed to the contemporary approach of modelling systems that are in equilibrium with a particular climate and atmospheric $\mathrm{CO}_{2}$ concentrations (e.g. Woodward et al., 1995; Xiao et al., 1998). The novel aspect of this research involves the aim that is three fold: (i) coupling ENSO related climatic variability to a vegetation simulation model, (ii) use of a simulation model to explore the hypothesis generated by a previous study based on time-series modelling of remotely sensed terrestrial vegetation data, and (iii) expanding on past Earth Systems research thus developing on the synergistic approach further.

It should be noted that previous geophysiological research into the coupling of vegetation and climate has mainly concentrated on the development of theoretical mathematical models (e.g. Svriezhev and von Bloh, 1997) of the tutorial genre, or further developments that dealt with investigating the evolution of terrestrial systems from a Darwinian perspective (e.g. Lenton and Lovelock, 2000). A common feature of these studies is that whilst stressing the need for synergistic approach in the natural world to investigate possible responsive mechanisms, they themselves did not address real-world Earth System scenarios. Hence, this investigation differs from previous geophysiological research as it focuses on a real-world scenario and builds upon work that involved the analysis of real-world terrestrial vegetation data.

\section{Methodology}

The Hybrid Version 4.1 is a combination of a gap model (whose dynamics are determined by the physiological processes at the individual tree level) and an ecological process model (whose dynamics are defined mostly by interspecies competition at the forest gap level) which is capable of simulating the transient behaviour of the terrestrial vegetation when subjected to natural or anthropogenic perturbations (Plummer, 2000). It is one of the most detailed 'forest gap' models class of process models; the only model without pre-determined vegetation types, as it generates its own temporal spread of vegetation types via gap, and competition dynamics that are incorporated within (Bossel, 1991). A full description of the original Hybrid model and its applications into the analysis of forest dynamics is described by Friend et al. (1993). Improvements to the original Hybrid model have illustrated the application of the Hybrid version 3.0 to study terrestrial ecosystem processes at the regional level (Friend et al., 1997) and on much larger scales at the global level (Friend and White, 2000) using the Hybrid Version 4.1. An attractive feature from the point of this paper is that the Hybrid Version 4.1 requires minimal or no additional site-specific parameterization excluding that of the climate (Friend and White, 2000). Hence, this provides a ready to use comprehensive simulation-modelling tool that enables scenarios of inter-annual climatic perturbations be tested for transient terrestrial vegetation systems, without any time consuming preprocessing (please refer to Table 1 for a description of the vegetation processes treated by the Hybrid v4.1 and the approaches taken).

Table 1. The Essential Vegetation Dynamics Components/ modules of Hybrid v4.1 as Inferred from Friend and White (2000)

\begin{tabular}{|c|c|}
\hline Process & Approach \\
\hline Competition & $\begin{array}{l}\text { Gap model (individuals compete for light, } \\
\text { water and nitrogen) }\end{array}$ \\
\hline \multirow[t]{2}{*}{ Photosynthesis } & $\begin{array}{l}\text { Vertically explicit, horizontally } \\
\text { homogeneous leaf: Farquhar biochemistry }\end{array}$ \\
\hline & Canopy: optimisation \\
\hline $\begin{array}{l}\text { Maintenance and } \\
\text { growth respiration }\end{array}$ & Nitrogen and empirical models \\
\hline $\begin{array}{l}\text { Stomatal } \\
\text { conductance }\end{array}$ & Empirical function \\
\hline Transpiration & Plot conductance end energy balance \\
\hline Nitrogen uptake & Demand/supply hypothesis \\
\hline Phenology & Heat-sum and day length \\
\hline Litter production & Empirically based \\
\hline \multirow[t]{3}{*}{ Allocation } & Optimised foliage area \\
\hline & Fixed foliage/sapwood area ratio \\
\hline & Fixed foliage/fine root ratio \\
\hline Tree shape & $\begin{array}{l}\text { Fixed diameter/ height allometry and form } \\
\text { factors }\end{array}$ \\
\hline Decomposition & Century model (empirical) \\
\hline Plot hydrology & Three layer scheme \\
\hline
\end{tabular}

Simulations were performed for a hypothetical terrestrial system that has a similar mean annual climate to the terrestrial South America. The terrestrial vegetation system was considered to be populated with four plant functional types, namely broadleaf evergreens, broadleaf dry-deciduous trees, $\mathrm{C}_{3}$ grasses and $\mathrm{C}_{4}$ grasses. These are identified to be as the main plant functional types of terrestrial South America (Cox et al., 2000; Friend and White, 2000). In other words the terrestrial system considered in this modelling study could be regarded as a simplified version of terrestrial South America that has the essential elements in terms of vegetation composition and climate. It should be noted that the other factors such as soil types; terrestrial hydrology and local physical geographical 
processes were not considered in this investigation, as the principal aim of this project is to show how resilience to ENSO could have arisen and not to create a model of terrestrial vegetation dynamics of South America.

The simulations assume an increase in atmospheric $\mathrm{CO}_{2}$ prescribed by the IPCC IRS92a scenario series (IPCC, 2001), which is neither an optimistic nor a pessimistic estimate of elevated anthropogenic $\mathrm{CO}_{2}$ concentrations. From the perspectives of a terrestrial system, soil carbon can take centuries to reach equilibrium with vegetation and climate (Friend and White, 2000), this would demand running the model for thousands of years to get it reach a steady state. Friend and White (2000) used the pre-industrial estimated equilibrium mean soil carbon content calculated by Post et al. (1982), to initialise the simulation. Similarly, they used global mean nitrogen values estimated at pre-industrial levels by Stedman and Shetter (1983). The same approach was followed here, thus reducing simulation time. Initializing carbon/nitrogen in this manner speeds up the convergence towards model equilibrium (Friend and White, 2000), and it does not constrain the model by altering the equilibrium levels. A baseline period is needed to define the observed climate with which climate change information is usually combined to create a climate scenario. When using the model results for scenario construction (or evaluation), the baseline period also serves as the reference period from which the modelled future change in climate is calculated (IPCC, 2001). Hybrid Version 4.1 has a stochastic weather generator as described by Friend (1998) that gives the possibility of using mean monthly climatic variables as input. Furthermore, for locations where ENSO signals are strong, weather generators can be successfully conditioned on ENSO phases and therein lays the potential for creating scenarios with changes in the frequency and amplitude of the ENSO events (IPCC, 2001). By conditioning on phases, either discretely (Wang and Connor, 1996) or continuously (Woolhiser et al., 1993), modelling can be performed to incorporate changes in the frequency and persistence of such events.

The baseline climate was created from mean annual climatic data for central Amazonia obtained from the literature published by Gash et al. (1996). A mean monthly data set for a hypothetical year was created as inferred from the above authors. The year's data was then repeated to create a 'norm' climatic data set. This data set assumes no interannual fluctuations influenced by ENSO and only shows seasonal fluctuations (as expected) for the climatic variables on the annual scale. Three separate story lines ${ }^{1}$, referred to as the 'norm', 'actual' and 'severe' were considered in the scenario development exercises for the analysis using the Hybrid Version 4.1 model. First, the scenarios based on the 'norm' climatic data set that assumes no interannual climatic variability. Second, the climatic scenarios based on the temporal analogues that

\footnotetext{
1 A narrative description of a scenario, which highlights the main scenario characteristics, relationships between key driving forces and dynamics.
}

incorporate the trends in the ENSO as inferred from the $\mathrm{SOI}^{2}$ values published by the University of East Anglia (United Kingdom), which will be referred to as the 'actual' story line from this point onwards. Thirdly, scenarios created by incurporating a synthetic SOI time-line to the 'norm' data set (after Manobavan and Lucas, 2003). The synthetic SOI series assumes increased frequency and amplitudes in the ENSO and hence this story line will be referred to as 'severe'.

\section{Results and Discussion}

The annual trends in the SOI trends are compared with the system's total biomass time-series output for the 'actual' climate scenario simulation in Figure 1. A two point moving average smoother was applied to the biomass output series to enable clear depiction of the changes in the system response to ENSO variability. As expected, the effects of the stress imposed by the El Niño events of the 1982/83, 1986/87, 1991/92 and 1997/98 can be observed (via decreasing biomass values), which, on an annual will look as if it is contradicting the hypothesis put forward by Manobavan et al. (2003). However, it should be emphasised that the modelling assumes that the ENSO variability continues to perturb the vegetation, therefore the model output(s) will show similar trends as exhibited by the climatic data that is used to drive the simulations. This in a sense illustrates the need for a much more holistic approach, where the results should be looked from a geophysiological perspective and the need for the 'human' consensus when it comes to arriving at conclusions (IPCC, 2001; Claussen et al., 2000).

Furthermore, due to the complexity of the Earth System, the contemporary analytical methods are incapable of providing for all the possibilities that need to be incorporated and it is inevitable in the modelling science to sacrifice some factors in order to enable better understanding regarding the connectivities of the variables of concern. This is called parameterisation in modelling science. It should be stressed that models are only abstracts of the reality and modelling should never (ever) be confused with prediction and/or the contemporary null-hypothesis testing approach prescribed to by geo-statisticians.

However, cleverly parameterised (e.g. The Daisy World Model, Watson and Lovelock, 1983) models can be effectively used to understand plausible conditions of the Earth System's future (IPCC, 2001), where different scenarios can be used in conjunction with results based on analysis of real-world data to understand the complete 'story'. Figure 2 compares the changes in the terrestrial system's Leaf Area Index $^{3}$ (LAI) for the system of concern under the 'norm' and

\footnotetext{
2 SOI is the accepted indicator of the phase and amplitude of the ENSO cycle (Rasmousson, 1985). Negative SOI values denote warm (El Niño) and positive values the cold phases (La Niña) of the ENSO.

3 Leaf Area Index is defined as the area of foliage per unit area of ground. This refers to the ratio of the area of the upper side of the leaves in a canopy projected onto a flat surface to the area of the surface under the canopy.
} 


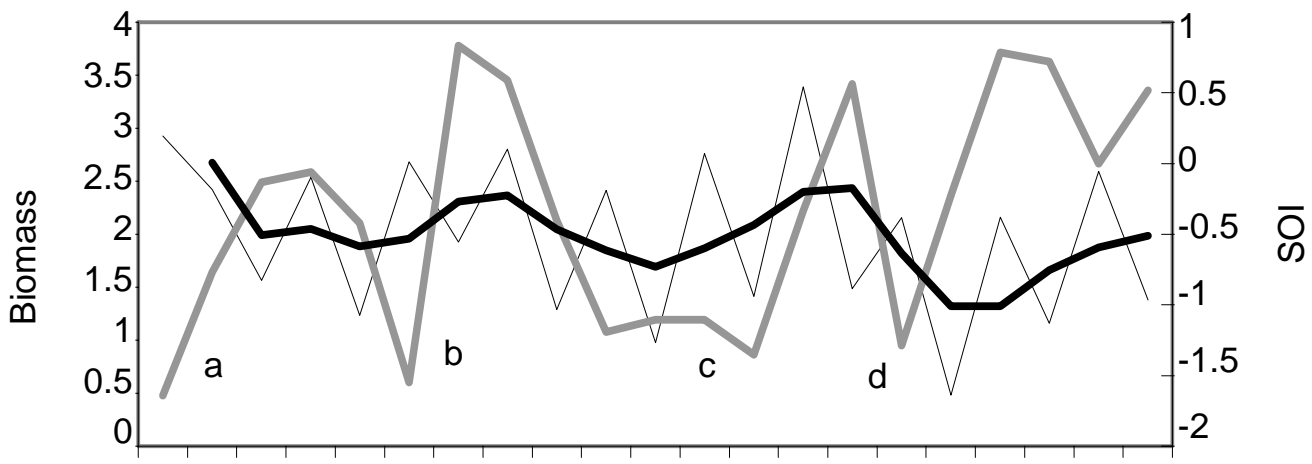

1982198419861988199019921994199619982000

Time (years)

Notes: The thick black solid line shows the biomass series (smoothed using a 2 point moving average to enable interannual trends to become prominent) and the grey line shows the SOI time-series. El Niño events are marked for reference (a. El Niño of 1982/83, b. El Niño of 1986/87, c. El Niño of 1991/92, d. El Niño of 1997/98).

Figure 1. A comparison of the temporal trends in the terrestrial system's biomass for the 'actual' climate scenario (thin solid line) with the yearly SOI time-series (grey line) for the period from 1982 till 2002.

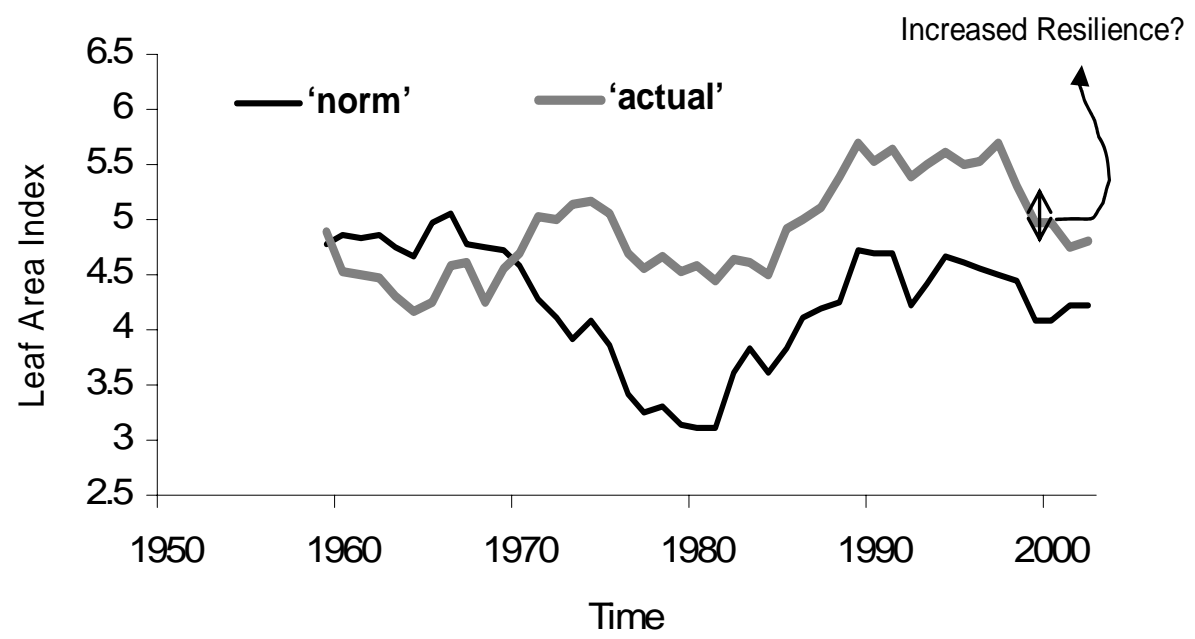

Figure 2. A comparison of the temporal trends in the terrestrial vegetation system's LAI for the 'norm' (black line) and 'actual' (grey line) storylines. 


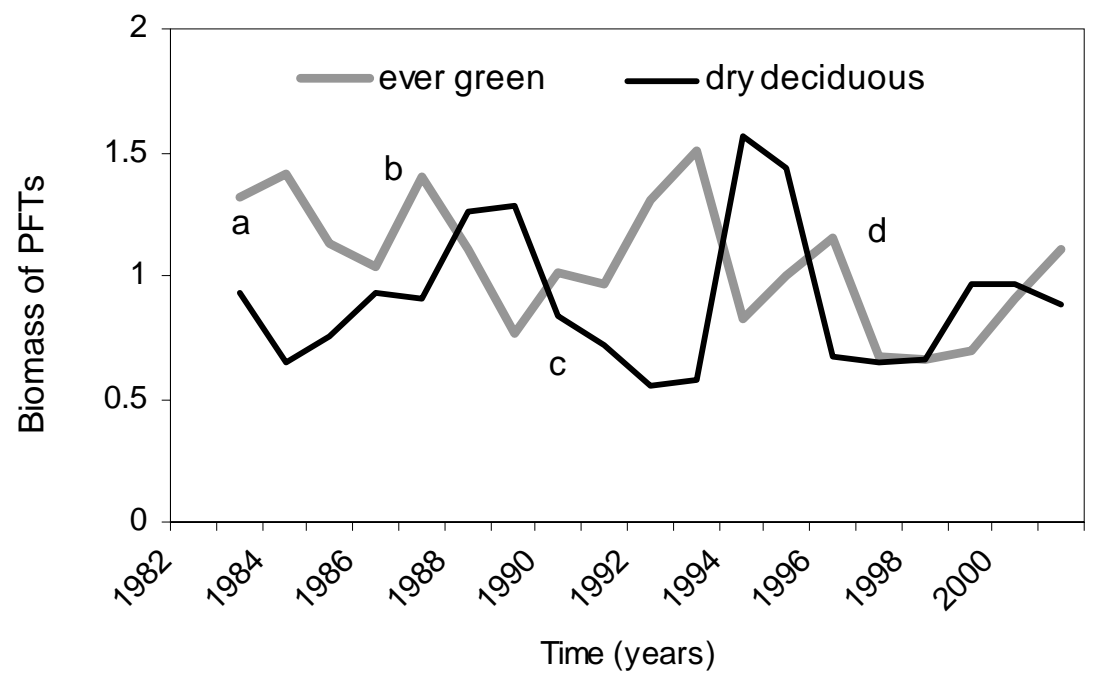

Notes: The grey line shows the changes in the biomass of the broadleaf evergreen trees and the black line the broadleaf dry deciduous trees. . El Niño events are marked for reference (a. El Niño of 1982/83, b. El Niño of 1986/87, c. El Niño of 1991/92, d. El Niño of 1997/98).

Figure 3. Comparisons of the temporal trends ('smoothed' using a 2 point moving average smoother to enable prominence to interannual trends) in the terrestrial system's plant functional type biomass for the 'actual' climate scenario.

'actual' storylines. The general increases in the system's LAI post 1980 (especially after 1990), is evident in the actual conditions storyline. Thus, the simulation supports the modelled NDVI trends by Manobavan et al. (2003) and this is an indication of the terrestrial system adjusting itself to interannual perturbations. Consequently, from a systemic perspective it can be inferred that cyclical perturbations (quasi-random ENSO fluctuations in this sense) are a necessity to initiate the process of terrestrial vegetation change and/or evolution, which is needed to retain the equilibrium of the system as a whole. El Niño events are considered to induce droughts in this investigation (so as in the case of Amazonia), which could have resulted in a reduction of photosynthetic biomass in the terrestrial vegetation (hence the decreases in NDVI/ LAI values).

In the 'actual' climate storyline El Niño events are considered to induce droughts, which impose water-related stress in the vegetation components of the terrestrial system. This in turn will be reflected in the composition of the plant functional types. Water stress will induce leaf senescence and leaf shedding. The broadleaf dry-deciduous trees are very sensitive to such drought conditions and show low LAI/biomass values (due to leaf shedding) during El Niño periods. Figure 3 compares the changes in the plant functional types over the period of investigation which shows a decrease in the biomass of broadleaf dry deciduous trees corresponding with (and/or soon after) the El Niño years of 1982/83, 1986/87, 1991/92 and 1997/98.

It should be noted that the $\mathrm{C}_{3}$ and $\mathrm{C}_{4}$ grasses were observed to be less dominant and were simulated to have negligible biomass values. This can probably be explained by the fact that the hypothetical area of investigation assumes a climate that is similar to the Equatorial South America, which is generally subjected to high precipitation levels and will be an unfavourable environment to the grasses for under wet conditions, trees are able to shade grasses thus shunting their growth, and in drought conditions are able to reach deeper soil water (Friend and White, 2000).

However, the persistence and longevity of the system under these interannual climatic perturbations is an issue that needs further exploration. A simulation assuming the 'severe' climatic scenario was performed for 1000 years. Figure 4 compares the temporal trends in the terrestrial system's biomass for the 'severe' climate storyline with the 'norm' climate storyline under the IS92a atmospheric $\mathrm{CO}_{2}$ concentration estimates for the period from 1873 till 2600. In both story lines, the system is simulated to be collapsing around the year 2380 (2378 AD under the 'norm' storyline and on the year 2380 for the 'severe' storyline). Which could be attributed to the terrestrial vegetation system exceeding its limits of tolerance (and/or geophysiological limits) to the increases in atmospheric $\mathrm{CO}_{2}$ concentrations around that period. This (partially) supports the hypothesis put forward by Cox et al. (2000), who predict an Amazon 'die-back' by year 2050. It should be noted that this investigation and the Cox et al. (2000) study do not account for dynamical spatial changes in the terrestrial vegetation spreads which could induce feedbacks to retain the stability (and the persistence) of the system (Lenton, 1998). Therefore, without further consideration of such spatial re-arrangements the 'die-back hypothesis' cannot be agreed 


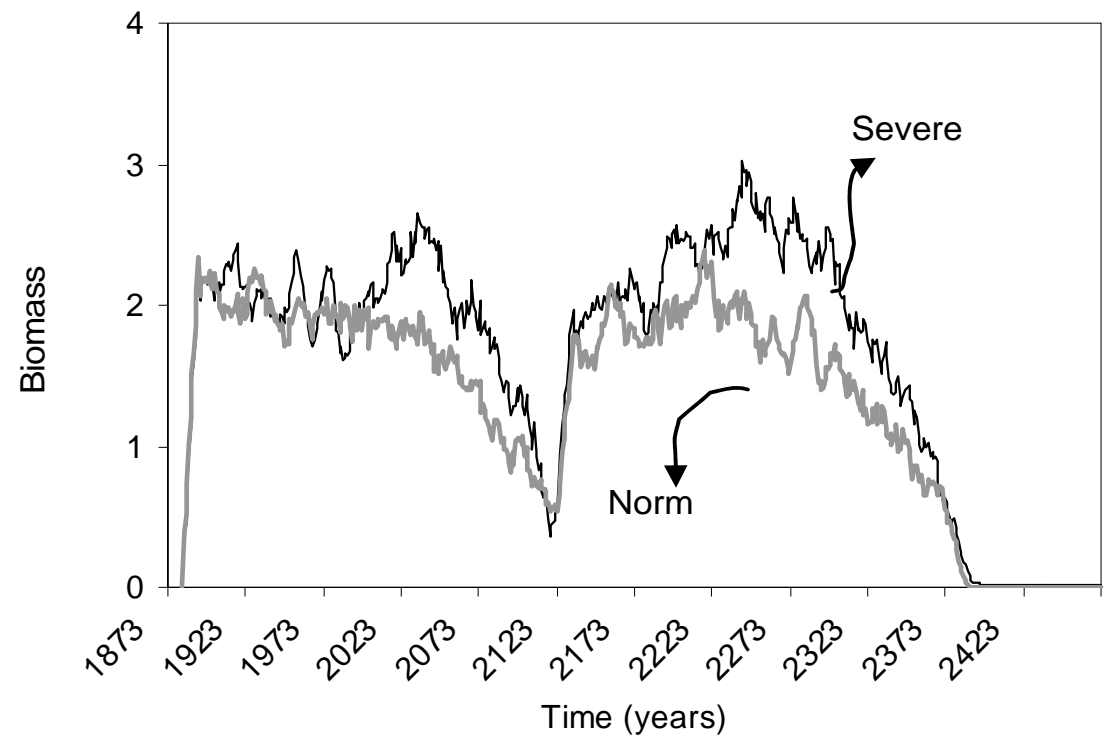

Notes: The outputs have been smoothed using a 10 point moving average smoother.

Figure 4. A comparison of the temporal trends in the terrestrial system's biomass for the 'severe' climate storyline (black line) with the norm climate storyline (grey line) under present atmospheric $\mathrm{CO}_{2}$ trends for the period from 1873 till 2600.

upon fully. However, the fact that there will be a definite end to this terrestrial vegetation system (sooner or later) cannot be contested. If not, it will be functioning entirely against the very basic principles of geophysiology (Lovelock, 1995, 1979; Lenton, 1998) and mathematical ecology, which prescribe that 'no system persists forever'. Which in other words indicates a definite beginning and an end to a system's existence. Consequently it can be argued that the results presented in Figure 4 are an indication of these basic concepts, as this is a modelling study the results cannot be considered as predictions but as illustrations/indications of the plausible future conditions of the system.

In other words, the relative high biomass values under the 'severe' storyline underline the effect of interannual climatic variability in stabilising the system within its geophysiological limits. From a systemic point of view it can be argued that the homeostasis or robustness/resilience of a system thrives on randomness, fluctuations or 'noise' (Heylighen, 2001; Ramakrishna, 2003). In this case, the increases in the ENSO phase and amplitudes over time, enhancing the homeostatic processes within the system. However the prime limiting factor here is the atmospheric $\mathrm{CO}_{2}$ concentration which acts to limit terrestrial vegetation growth. This implies that at present increasing $\mathrm{CO}_{2}$ concentration trends, there is a possibility that the system could possibly collapse around/or after the 2370s.

Cao and Woodward (1998) state that, an increase in the atmospheric $\mathrm{CO}_{2}$ will initially increase global net ecosystem production significantly, but that this response will decline as the fertilisation effect becomes saturated and is diminished by climatic factors. Further more, these anthropogenically induced increases in the atmospheric $\mathrm{CO}_{2}$ may make a further negative contribution to the derangement of the Earth System, by inducing a physiological response of the global vegetation - a reduced stomatal conductance, which suppresses transpiration (Sellers et al., 1996). Moreover, a $\mathrm{CO}_{2}$ enriched atmosphere and the corresponding change in climate may also alter the density of vegetation cover, thus modifying the physical characteristics of the land surface to provide yet another climate feedback (Betts, 2000). Further developments along these lines are impossible without proper consideration of the respective spatial-temporal mechanisms involved, which is beyond the scope of this paper.

\section{Conclusions}

An investigation of simulating terrestrial vegetation responses to ENSO related inter-annual climatic variability using a mechanistic vegetation model is presented in this paper. Simulations were performed for a hypothetical terrestrial system similar to terrestrial South America (that has a mean climate that is similar to that of central Amazonia) further confirm the possibility that the vegetation could have become resilient to ENSO over time. This can be attributed to the fertilization effect induced by the increasing atmospheric $\mathrm{CO}_{2}$ concentrations. It is also seen that whilst inducing the increased vegetation activity, the atmospheric $\mathrm{CO}_{2}$ concentrations also act as a limiting factor, as the system is simulated to be collapsing once it exceeds its limits of tolerance to increases in $\mathrm{CO}_{2}$ concentrations. This also adds to the argument 
that the homeostasis or robustness of a system thrives on randomness, fluctuations or 'noise' which implies that these kind of random shocks are necessary for the stability and persistence of the terrestrial vegetation system.

Simulations also illustrate that the terrestrial vegetation system tries to absorb inter-annual shocks by adjusting its vegetation components in the temporal domain (Figure 3) thus providing a mechanistic explanation to the geophysiological behavior of the terrestrial vegetation system. A change in the composition of the plant functional types is observed during El Niño years, where the biomass of the broadleaf dry deciduous trees decreases. This in other words, indicates that the simulated terrestrial vegetation system responds to inter-annual climatic variability by re-arranging its components in the temporal domain, through a process where 'natural selection' could determine the dominance of a functional type (Lenton, 1998). El Niño induced droughts can be visualized as the natural selective mechanism from the context of this paper. This could lead to ecological succession that may involve the onset of regulatory feedbacks (Hamilton, 1996). These internal changes in the terrestrial vegetation system, involving feedbacks on plant functional type growth and natural selection, may in turn drive changes in climate (Lenton, 1998). However, these arrangements and re-arrangements in the realistic sense will happen through space and time. It should be once again noted that the Hybrid Version 4.1 is incapable of simulating the spatial processes. Furthermore, it is stressed that the concepts of natural selection, change and/or evolution should be looked from a geophysiological perspective for terrestrial systems, rather than the species level view which is often adhered to by ecologists and biologists (Lovelock, 1995). Further discussion along these lines is beyond the limits of this paper.

A new term, 'geophysiological limits' is introduced in this paper. Lovelock (1995, 1979), in his classical works pertaining to the development of Earth System Science emphasises on the need for the emergence of the field of geophysiology, which is the study of the processes within the Earth System from a physiological context. In biology, any living system or organism is said to have a lower and upper limit of tolerance for any environmental variable that affects its physiology, which is defined as the physiological limit for that particular variable. Based on these, the term 'geophysiological limits' is proposed. Which, in other words, explains that for a particular terrestrial system there are geographical limits within which it can exist (e.g. the woodlands dominated by Teak - Tectona grandis can only grow in tropical regions near the equator) and that, there are certain physiological limits to the components of the said system from a biological perspective (e.g. Tectona grandis cannot survive in sub-zero temperatures). It should be noted that the geographical and physiological limits to a particular organism are interconnected where the latter determines the extent of the former.

In conclusion, this paper detailed the application of the Hybrid Version 4.1 as an analytical tool to investigate terres- trial vegetation dynamics to ENSO perturbations from a comprehensive mechanistic-geophysiological perspective. The hypothesises put forward by previous research were further explored in this paper and, this in a sense stresses the fact that a holistic understanding of the Earth System can only be possible through a synergistic interdisciplinary approach.

Acknowledgments. The authors wish to thank Dr. Andrew Friend for providing the code for the Hybrid Version 4.1. Special thanks go to Drs. Peter Levy and Richard Betts for the extremely stimulating discussions on terrestrial vegetation modelling. This work has been carried out as part of a Centre for Earth and Environmental Sciences Research (Kingston University, United Kingdom) funded studentship (SLXGL28/1026) awarded to Manoharadas Manobavan. The authors wish to dedicate this piece of work to all the lost tropical dry deciduous forests of Batticaloa in the East of Sri Lanka.

\section{References}

Arora, V. (2003). Decreased heterotrophic respiration reduced growth in atmopsheric $\mathrm{CO}_{2}$ concentration. IGBP News Lett., 54, 21-22.

Asner, G.P., Townsend, A.R. and Braswell, B.H. (2000). Satellite observation of El Niño effects on Amazon forest phenology and productivity. Geophys. Res. Lett., 27, 981-984.

Betts, R.A. (2000). Offset of the potential carbon sink from boreal forestation by decreases in surface albedo. Nat., 408, 187-190.

Bossel, H. (1991). Modelling forest dynamics: moving from description to explanation. For. Ecol. Manage., 42, 129-142.

Boyd, D.S. and Duane, W.J. (2001). Exploring spatial and temporal variation in middle infrared reflectance measured from the tropical forests of West Africa. Int. J. Remote Sens., 22, 1861-1878.

Cao, M. and Woodward, I.F. (1998). Dynamic responses of terrestrial ecosystem carbon cycling to global climate change. Nat., 393, 249-252.

Claussen, M., Ganopolski, A., Schellnhuber, J. and Cramer, W. (2000). Earth system Models of Intermediate Complexity. Global Change: IGBP News Lett., 41, 4-6.

Cox, P.M., Betts, R.A., Jones, C.D., Spall, S.A. and Totterdell, I.J. (2000). Acceleration of global warming due to carbon-cycle feedbacks in a coupled climate model. Nat., 408, 184-187.

Dawson, A.G. and O'Hare, G. (2000). Ocean-Atmosphere circulation and Global Climate: The El Niño Southern Oscillation. Geogr., 85, 193-208.

Friend, A.D. (1998). Parameterisation of a global daily weather generator for terrestrial ecosystem and biogeochemical modelling. Ecol. Model., 109, 121-140.

Friend, A.D. and White, A. (2000). Evaluation and analysis of a dynamic terrestrial ecosystem model under pre-industrial conditions at the global scale. Global Biogeochem. Cycles, 14, 1173-1190.

Friend, A.D., Schugart, H.H. and Running, S.W. (1993). A physiology based gap model of forest dynamics. Ecol., 74, 792-797.

Friend, A.D., Stevens, A.K., Knox, R.G. and Cannell, M.G.R. (1997). A process-based, terrestrial biosphere model of ecosystem dynamics (Hybrid v3.0). Ecol. Model., 95, 249-287.

Gash, J.H.C., Nobre, C.A., Roberts, J.M. and Victoria, R.L. (Eds.) (1996). Amazonian Deforestation and Climate, John Wiley \& Sons, New York.

Hamilton, W.D. (1996). Gaia’s benefits. New Sci., 151, 62-63.

Hansen, P.M. and Schojoerring, J.K. (2003). Reflectance measurement of canopy biomass and nitrogen status in wheat crops using normalized difference vegetation indices and partial least squares regression. Remote Sens. Environ., 86, 542-553. 
Haxeltine, A. and Prentice, I.C. (1996). BIOME3: an equilibrium biosphere model based on ecophysiological constraints, resource availability and competition among plant functional types. Global Biogeochem. Cycles, 10, 693-709.

Heylighen, F. (2001). The science of self-organisation and adaptivity, in The Encyclopaedia of Life Support Systems, EOLSS Publishers Co. Ltd.

IGBP (International Geosphere-Biosphere Programme) (2003). Boxed editorial comment. IGBP News Lett., 54, 21.

IPCC (2001). Climate Change: The Scientific Basis, Contribution of Working Group 1 to the Third Assessment Report of the Intergovernmental Panel on Climate Change, J.T. Houghton, Y. Ding, D.J. Griggs, M. Noguer, P.J. Van Der Linden, X. Dai, K. Maskell \& C.A. Johnson (Eds.), Cambridge University Press, Cambridge, United Kingdom and New York.

Knorr, W. (2000). Annual and interannual $\mathrm{CO}_{2}$ exchanges of the terrestrial biosphere: process-based simulations and uncertainties. Global Ecol. Biogeogr., 9, 225-252.

Lenton, T.M. (1998). Gaia and Natural selection. Nat., 394, 439- 447.

Lenton, T.M. and Lovelock, J.E. (2000). Daisyworld is Darwinian: Constraints on adaptation are important for planetary self-regulation. J. Theor. Biology, 206, 109-114.

$\mathrm{Li}$, Z. and Kafatos, M. (2000). Interannual variability of vegetation in the United States and its relation to El Niño Southern Oscillation. Remote Sens. Environ., 71, 239-247.

Lovelock, J.E. (1979). Gaia-A New Look at Life on Earth, Oxford University Press.

Lovelock, J.E. (1995). The Ages of Gaia: A Biogeography of Our Living Earth, Cambridge University Press.

Manobavan, M. and Lucas, N.S. (2003). A climatic scenario development study using remotely sensed vegetation data, in The Proc. of the GIS Research UK, $11^{\text {th }}$ Annual Conference, J. Wood (Ed.), City University, London, $9^{\text {th }}-11^{\text {th }}$ April, 2003, pp. 176-180.

Manobavan, M., Lucas, N.S., Boyd, D.S. and Petford, N. (2003). The sensitivity and responses of terrestrial South American vegetation to interannual climate variability induced by the ENSO. $J$. Environ. Inf., 2(2), 1-10.

Ni, J., Stykes, M.T., Prentice, I.C. and Cramer, W. (2000). Modelling the vegetation of China using the process-based equilibrium terrestrial biosphere model BIOME3. Global Ecol. Biogeogr., 9, 463-479.

Peng, C.H. (2000). From static biogeographical model dynamic global vegetation model: alobal perspective on modelling vegetation dynamics. Ecol. Model., 135, 33-54.

Plummer, S.E. (2000). Perspectives on combining ecological process models and remotely sensed data. Ecol. Model., 129, 169-186.

Post, W.M., Emanuel, W.R., Zinke, P.J. and Stangenberger, A.G. (1982). Soil carbon pools and world life zones. Nat., 298, 156-159.

Potter, C.S. and Klooster, S.A. (1999). Dynamical global vegetation modelling for prediction of plant functional types and biogenic trace gas fluxes. Global Ecol. Biogeogr., 8, 473-488.

Pratchett, T. (1998). The Last Continent-A Discworld Novel, Corgi Books, Great Britain.

Rasmusson, E.M. (1985). El Niño and variation in climate. Am. Sci., 73, 168-177.

Robock, A. (2000). Volcanic eruptions and climate. Rev. Geophys., 38, 191-219.

Sellers, P.J., Bounoua, L., Collatz, G.J., Randall, D.A., Dazlich, D.A., Los, S.O., Berry, J.A., Fung, I., Tucker, C.J., Field, C.B. and Jensen T.G. (1996). Comparison of radiative and physiological effects of doubled atmospheric $\mathrm{CO}_{2}$ on climate. Sci., 271, 1402-1406.

Stedman, D.H. and Shetter, R. (1983). The global budget of atmospheric nitrogen species, in S.S. Schwartz (Ed.) Trace Atmospheric Constituents: Properties, Transformation and Fates, John Wiley \& Sons, New York, pp. 411-454.

Svirezhev, Y.M. and von Bloh, W. (1997). Climate, vegetation, and global carbon cycle: the simplests zero-dimensional model. Ecol. Model., 101, 79-96.

Wang, Y.P. and Connor, D.J. (1996). Simulation of optimal development for spring wheat at two locations in Southern Australia under present and changed climate conditions. Agr. For. Meteorol., 79, 9-28.

Watson, A.J. and Lovelock J.E. (1983). Biological homeostasis of the global environment: the parable of the Daisy world. Tellus, 35B, 284-289.

Wellens, J. (1997). Rangeland vegetation dynamics and moisture availability in Tunisia: An investigation using satellite and meteorological data. J. Biogeogr., 24, 845-855.

Woodward, F.I. Smith, T.M. and Emmanuel, W.R. (1995). A global land primary productivity and phytogeography model. Global Biogeochem. Cycles, 9, 471-490.

Woolhiser, D.A. Keefer, T.O. and Redmond, K.T. (1993). Southern Oscillation effects on daily precipitation in the southwestern United States. Water Resour. Res., 29, 1287-1221.

Xiao, X.J.M., Mellilo, D.W., Kicklighter, A.D., McGuire, R.G., Prinn, C., Wang, P., Stone, H. and Sokolov, A. (1998). Transient climate change and net ecosystem production of the terrestrial biosphere. Global Biogeochem. Cycles, 12, 345-360. 